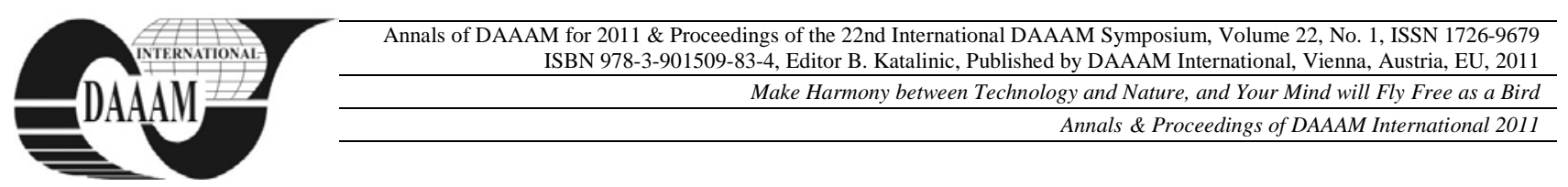

\title{
MATERIAL SURFACE CHARACTERIZATION USING LAWS DESCRIPTORS
}

\section{SUAREZ CASTRILLON, S[ir] A[lexci]; BARREIRO, J[oaquin]; ALEGRE, E[nrique]; GARCIA ORDAS, M[aria] T[eresa] \& GARCIA - OLALLA, O[scar]}

\begin{abstract}
A vision system is proposed that employs texture descriptors to classify different materials used in industrial processes. Five types of materials were tested: concrete, sandstone, wood, metal and paper. Haralick descriptors were used as texture descriptors obtained from the coocurrence matrix and also the first order descriptors combined with energy of Laws. Classification was carried out using linear discriminant analysis. Results show the good reliability of the R5R5 Laws mask, which achieves higher hit rates that those obtained when using the coocurrence matrix.
\end{abstract}

Key words: coocurrence matrix, laws, roughness, texture descriptors, material classification

\section{INTRODUCTION}

The analysis of defects, the identification and control of materials is critical in the production line of numerous industrial applications to reduce costs and increase productivity. It is especially important in sectors as recycling industry or the stage of retirement in product lifecycle. In this context, the use of automatic systems based on vision is very interesting in order to carry out a full control.

The texture of materials was analyzed to discriminate one type of materials from others using the information extracted from images of products. Inspection of different materials by means of texture analysis has been studied for some industrial processes as textile, food, paper, leather, wood, cork, ceramic, medicine or metal production (Morala et al., 2011).

In the field of textile industry, one of the reference works is the one developed by Latif-Amet et al. (Latif et al., 2000). The authors apply the coocurrence matrix (GLCM) to detect defects in fabrics, using the Wavelet transform and extracting the Haralick descriptors. Other work in the field of textile is the one developed by Baykut et al. (Baykut et al., 1998), where authors apply different texture methods like GLCM, Laws, hidden models of Markov and Fourier transform. In this work the results indicate the success in the use of descriptors to detect defects in textile, obtaining the best results whith the Hidden Markov Models. Also, Bodnarova et al. (Bodnarova et al., 2000) deal with detection of defects in fabrics using GLCM to assure a high quality final product. After applying texture techniques it was proved that the use of GLCM achieves hit rates between $64 \%$ and $88 \%$.

Also in materials such as glass, ceramic, polymers or construction residuals different methods of texture feature extraction have been analyzed using vision methods.

A paper published by Novak and Hocenski (Novak \& Hocenski, 2005) explores the feature extraction in ceramic materials; this work extracts features from the local binary pattern (LBP).

Also, it is worth mentioning the work of Lopez et al. (Lopez et al., 2008), which automates the processes of superficial degradation so much in tiles, granite and wood.

The mentioned papers make evident the importance of nowadays vision systems in industrial processes. That is the reason behind our research.
In this paper we show the results of evaluating different texture descriptors. We conclude that with a single Laws descriptor mask (R5R5) the aforementioned materials can be classified correctly. The hit rate is very high; near to $100 \%$ in some cases.

The paper has been structured in the following sections. In section 2 a description of the devices for adquisition of images is presented, as well as the group of analyzed data. In section 3 the implemented descriptors are described. In section 4 the results obtained in the classification are explained.

\section{METHODOLOGY}

\subsection{Resources used}

Next paragraphs describe the devices used for acquiring the images of materials, in particular for metallic parts. These images were stored in the texture database of the Group of Artificial Vision and Recognition of Patterns (VARP) at the University of León.

Metallic parts were cylinders. Several cutting parameters were varied in order to obtain a wide range of surface finish and roughness values. The images were acquired using an AVT Oscar F-810C camera with a $2 \mathrm{X}$ zoom. The assembly was composed of an industrial zoom 70XL OPTEM, with a extension tube of $1 \mathrm{X}$ and $0.5 \mathrm{X} / 0.75 \mathrm{X} / 1.5 \mathrm{X} / 2.0 \mathrm{X}$ OPTEM lens.

The lightening system was a source of regulated light DCR RIII FOSTEC. To avoid shines a system SCDI of diffuse illumination NER SCDI-25-F0 was used and the technique of coaxial illumination was implemented. Resolution of captured images was 3372x2469 pixels. Later on it was reduced at $578 \times 586$ by means of interpolation.

\subsection{Data set used}

Five different materials were used in the tests. A total data set of 185 images was used with a resolution of 578x586 pixels. Table 1 shows the number of images for each material. A 75\% of full data set was selected for training and a $25 \%$ for testing. Classification was carried out using linear discriminant analysis (LDA). Figure 1 shows some images of the materials tested.

\section{DESCRIPTORS TESTED}

\subsection{Coocurrence matrix}

This method obtains information about the combined probability that a pair of pixels satisfies a certain condition. The equation used is the related to the normalized matrix:

$$
N_{d}(i, j)=\frac{C_{d}(i, j)}{\sum_{i} \sum_{j} C_{d}(i, j)}
$$

where $\mathrm{C}_{\mathrm{d}}$ is the coocurrence matrix.

From the coocurrence matrix some texture descriptors were obtained. The descriptors used in this case were: entropy, second angular moment, contrast, homogeneity, variance, 
correlation, sum average, sum variance, sum entropy, difference variance, difference entropy, first correlation measure, second correlation measure. The directions $0^{\circ}, 45^{\circ}$, $90^{\circ}$ and $135^{\circ}$ grades were selected in the experiments to extract the information, all at fix distances of 1,3 and 5 pixels. Therefore, a vector called SC with 13 features was obtained for each direction and distance.
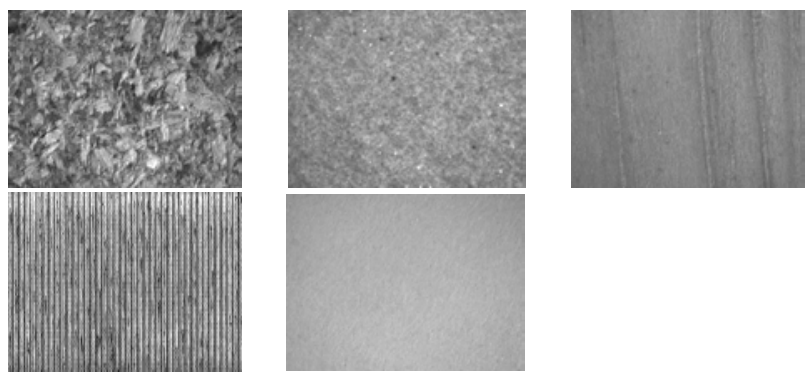

Fig. 1. From left to right: concrete, sandstone, wood, metal, paper.

\begin{tabular}{|c|c|c|c|}
\hline Type & $\begin{array}{c}\text { Num. } \\
\text { images }\end{array}$ & Type & $\begin{array}{c}\text { Num. } \\
\text { images }\end{array}$ \\
\hline $\begin{array}{c}\text { Concrete } \\
\text { Sandstone } \\
\text { Wood }\end{array}$ & 40 & Metal & 45 \\
30 & Paper & 30 \\
\hline
\end{tabular}

Tab. 1. Image data set used.

\subsection{Laws descriptors}

The method of Laws consists on the convolution of the image with several kernels. Each kernel stands out a feature of different texture: $\mathrm{L}=$ pondered average, $\mathrm{E}=$ borders, $\mathrm{S}=$ shape or stain, $\mathrm{W}=$ wave, $\mathrm{R}=$ ripples or roughness, $\mathrm{O}=$ oscilation.

When a original image is convolved with a kernel, the new images will have values related to the corresponding kernel feature. In this work neighborhoods of $5 \mathrm{x} 5$ were used, since they provided the best performance; the values of the kernels

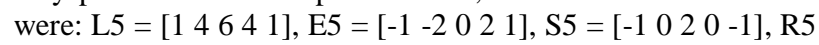

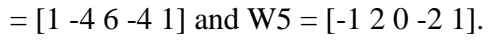

\section{RESULTS AND CONCLUSIONS}

In order to select the best kernel and the best statistical descriptor, a previous test was carried out over metallic materials. In this test, images were divided into two classes, one related to low roughness $(<4 \mu \mathrm{m})$ and the other one to high roughness $(>4 \mu \mathrm{m})$. The total amount of images were 1840 and 1941, respectively; a subset of $75 \%$ was selected for training and the other $25 \%$ for testing. The results of this previous test showed that the best kernel was the R5R5 with an error rate of (12,33\%), followed by E5E5 (13,99\%) and E5R5 (15,66\%), in all cases combined with the standard deviation statistical. More detail of this previous test can be found in the work of Suárez (Suarez et al., 2010).

Additionally, the results of classifying different materials (paper, wood, metals and others) demonstrated the discriminant power of the R5R5 kernel together with the standard deviation. This combination ouperforms the results obtained with the SC vector mentioned previously. The combination of R5R5 kernel and standard deviation let to discriminate some materials from others, achieving an average hit rate of $75,8 \%$ for all materials (93,8\% for wood).

The results achieved with the SC vector of the coocurrence matrix are lower, with an average hit rate for all materials of only $62,2 \%$. Again, wood is the best recognized material with a hit rate of $100 \%$.

Figure 2 shows the comparative analysis of the tested descriptors, where the combination of R5R5 mask with the standard deviation stands out clearly by its performance. The difference in the hit rate was minimum when increasing the number of descriptors using different directions (grades) and distances for the SC vector. The best results were with a distance of 1 and $0^{\circ}$ (see Figure 2).

Conclusions of the research indicate that a single descriptor allows classifying different materials as a function of their texture. In future works other descriptors will be evaluated to improve still more the hit rate. Also, a correlation between the values derived from the proposed descriptors and the Ra parameter we will be looked for to obtain a roughness measure using only the information contained in images.

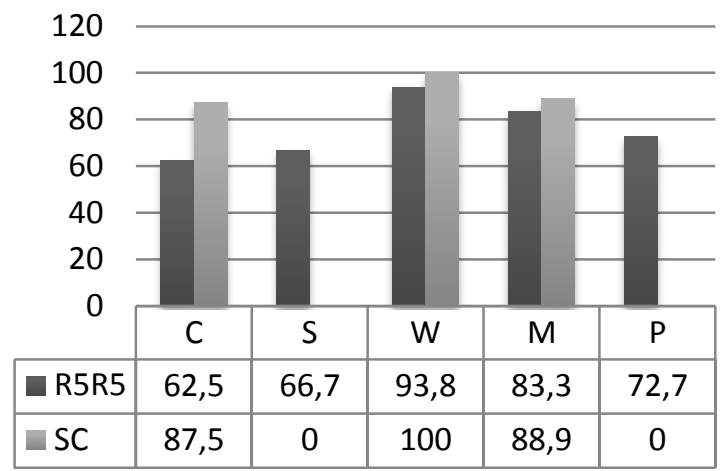

Fig. 2. Classification percentage comparing R5R5 mask and SC vector, both with standard deviation $(\mathrm{C}=$ concrete, $\mathrm{S}=$ sandstone, $\mathrm{W}=$ wood, $\mathrm{M}=$ metal, $\mathrm{P}=$ paper).

\section{ACKNOWLEDGEMENTS}

This work has been supported by the project DPI200908424 from the Spanish Ministry of Science and Innovation.

\section{REFERENCES}

Baykut A.; Ozdemir, S.; Ertuzun, A.; Ercil, A. \& Meylani R. (1998). Comparative Evaluation of Texture Analysis Algorithms for Defect Inspection of Textile Products, Proceedings of Intl. Conf. on Pattern Recognition. August 17-20, Brisbane, ISBN: 0818685123, pp. 1738-1740, Australia

Bodnarova, A.; Bennamoun, M. \& Kubik, K. (2000). Suitability Analysis of Techniques for Flaw Detection in Textiles using Texture Analysis. Pattern Analysis and Applications. (3) (254-266)

Latif-Amet, A.; Ertüzün, A. \& Ereçil, A. (2000). An efficient method for texture defect detection. Image Vision Computing, 18 (5) (377-387)

López, F.; Valiente, JM.; Prats, JM. \& Ferrer, A. (2008). Performance evaluation of soft color texture descriptors for surface grading using experimental design and logistic regression. Pattern Recognition, 41 (5) 1744 -1755

Morala, P.; Barreiro, J. \& Alegre, E. (2011). A evaluation of surface roughness classes by computer vision using wavelet transform in the frequency domain. The Intl. J. Advanced Manufacturing Technology. Accesible on-line: DOI: 10.1007/s00170-011-3480-6

Novak, I. \& Hocenski, Z. (2005). Texture feature extraction for a visual inspection of ceramic tiles, Proceedings of IEEE Intl. Symposium on Industrial Electronics (ISIE), June 2023, Dubrovnik, (3) pp 1279-1283, Croatia

Suárez, S.A.; Alegre, E.; Barreiro, J.; Morala-Argüello, P. \& Fernández, L. (2010). Surface roughness classification in metallic parts using Haralick descriptors and quadratic discriminant analysis, Proceedings of $21^{\text {st }}$ Intl. DAAAM Symposium, October 20-23, Zadar, Croatia, ISBN: 17269679, Katalinic, B. (Ed.), pp. 1241-1242, Vienna 